\title{
Is Bitcoin Trading Globally Efficient? A Daily Analysis between Three Exchanges in the Period 2017 To 2019
}

\author{
Denis Forte ${ }^{1}$, Eli Hadad Junior ${ }^{2}$ and João Valente Filho ${ }^{3 *}$ \\ 1,2,3 Mackenzie Presbiterian University, São Paulo, Brazil
}

\begin{abstract}
.
Cryptocurrencies are traded worldwide simultaneously in several world markets. This allows to compare in real time the prices traded and the implied volatility in different locations. The main contribution of this article seeks to address market studies between the encrypted digital market and the analysis of the Bitcoin time series, in the light of the Market Efficiency and Behavioral Finance Hypothesis. This research also helps to answer whether the bitcoin market has a long-term balance between bitcoin and the different quotes in its local currencies. Based on economic statistics tools, using data collected from exchanges in Brazil, United States and Europe. You can see that HEM is also present in the cryptocurrency market. You can see that this theory integrates with Financial Finance, since financial market studies and theories exist before disruptive converged crypto market surgeries suitable for behavioral finance studies.
\end{abstract}

Keywords: BITCOIN; BEHAVIORAL FINANCE; EFICIENT MARKET HIPOTESIS

\section{Introduction}

Cryptocurrencies are traded worldwide simultaneously in several world markets, called Exchanges. This allows us to compare real-time trading prices and implied volatility of the same in different locations. This information is theoretically relevant and also from the point of view of global regulatory bodies, in order to prevent market manipulation and other derogatory behavior of the agents.

The main contribution of this paper seeks to answer the lack of research between the digital market of cryptocurrencies by the analysis of time series of daily Bitcoin closing, in light of Modern Finance Theory that is based on Market Efficiency Hypothesis (HEM) and Finance Behavioral.

The research analyzes the exchanges that trade Bitcoin under the analysis framework of HEM and the basic concepts of behavioral finance. In summary, test the various market efficiency levels is to reduce to test the past series and its predictive power for the new price. In addition, test the volatility of different markets and compare them.

Since the introduction of cryptocurrencies is a financial innovation, another contribution of this study is to analyze the applicability of technical financial analyzes in this new emerging 
market, which is similar to a mix of exchange rate analysis and capital market analysis, in the light of concepts of Behavioral Finance.

According to Fama (1970) the HEM maintains that prices have a rational basis in terms of fundamentals as the great profit forecast or evaluation of the standard deviation of the risk factors faced by corporations. As the theory considers indexes rationally determined, they change from one day to another mainly by genuine news, that is, by nature, essentially unpredictable.

Santos (2005) suggests that, in practice, the financial market coexist linear and nonlinear structures capable of periodic bifurcations and violent behavior, with well-behaved macroeconomic structures, however, the combination of these factors ultimately, form a chain shows the market efficiency is an issue yet to know analyzed by researchers, which confirms the need and importance of this research.

Lima (2003) suggests that financial innovations will always develop to meet the demand for liquidity and lower risk, originating more and more from public fund managers, giving rise to a price dynamic that drives market prices further and further away of their fundamentals, generating price volatility that has little to do with their own oscillations of a hypothetically rational market. From these considerations it is not surprising that constitute "new forms of rationality" increasingly distant from classic or conventional design rationality.

When dealing with risk, according to Plihon (1995), systemic risk becomes increasingly greater as a large part of the operations are out of control. This observation applies in the case of free derivatives markets, which the wild growth over the past few years is worrying. On the one hand it seems that the authorities are not ready to tax speculative operations, on the other would not be surprising that the market risk should be the subject of an interim control increasingly strict. The recent inclusion of such risks in the forms of solvency tax calculation is a first step in this direction.

That said, the research helps to answer the hypotheses. In the bitcoin market is there a longterm balance between bitcoin and the different quotes in your local currencies?

The importance of studying the cryptocurrencies behavior within the financial market, shows not only its relevance for the size of its market, but also for the integration in traditional financial markets, technology and constant evolution of the entire system. The identification of cointegration markets can provide new insight into practical functions of a process that does not have opening and closing and is exposed to the inherent risks and sensitive facts and behavioral effects such as exchange and stock markets, for example.

Behavioral effects such as calendar, Monday, contagion, herd, corroborate the relevance on cryptocurrencies research, since the scarcity of studies on this subject and, also, to identify what is the position of the cryptocurrency in the globalized market and constant, frequent by the time they occur. Speculations, just as they occur in the traditional market, are easily perceived as Bitcoin trading exchanges do not close and are therefore sensitive to relevant facts and can incorporate these facts into their price instantly and within the market cointegration chain, all prices where they are traded can also suffer the same perception due to the same sensitivity.

Even as justification and research relevance, one can see several studies on financial traditional market, comes from the study in-depth assets, indices and even complete entire markets, some inexhaustible subjects like Hypothesis of Market Efficiency, Capital Structure, Cost Capital, among others, however, the research related to a new way financial disruptive, 
such as cryptocurrencies are scarce, related tests and we met are the same as financial markets, testing and perfecting the known concepts.

\section{Theoretical Reference}

\subsection{Cryptocurrency and Governance in The Digital Market}

Nakamoto (2008) shows how the proof-of-work algorithm works, creating the new coins in the Bitcoin network and how this technology could be the new monetary system, independent and decentralized, as it uses the network members to carry out the "mining", that is, the validation through the algorithms created by the system.

According to the author, the proposal for a solution to the hacking and ownership of resources handled by the internet network, since anything on the network has a risk of being "hacked" was to create a network that records the time the transactions through encrypted shipping addresses, called hashes, making a record that can't be changed without redoing all the work test.

Finally, the author states that an indelible form of registration is the time stamp to any digital object. It can be the standard time (Greenwich) for worldwide transactions. All characters are connected as evidence and file validation, Hash (as described the transaction code) relates to a higher code, such as the check digits of the Brazilian CPF. By using encryption SHA 256 one way, the main feature of the Hash is to be irreversible and can't get the original code from the hash.

It can be concluded, therefore, that the cryptocurrency creation process followed a protocol that allows the creation of new products with the same technological process, the blockchain and that it has a level of security and reliability accepted by the market, thus conferring characteristics of currency (transaction, security, control).

\subsection{Efficient Market Hypothesis (EMH)}

According to Fama (1970), the definition of an efficient market is one in which the price of the traded assets always fully reflects the information available about the assets. The power of the efficient markets hypothesis is significant, since this hypothesis rules out the possibility of greater gains that are based only on this information made available.

Intrinsically, in the concept of Fama's efficient market theory (1970), investors are considered to assume a rational role in their investments and to evaluate and price assets in the same way. Random investments are attributed to non-rational investors and do not have significant effects on the prices charged by the market. These irrational investors, having common characteristics, produce a greater presence of rational arbitrage, eliminating their influence on prices.

Rabelo (2004), in its extreme form, states that the theory of efficient markets says that all securities are always correctly priced, which means that the market as a whole would exercise rationality in pricing. 
The Bone Research (2002), sought to follow a specific method of an empirical model on the evidence of the different forms of weak efficiency hypothesis in the Brazilian stock market. The tests comprise heteroscedasticity and / or autocorrelation and normality of the residuals.

\subsubsection{Strong, Semi-Strong and Weak and Random Walk}

According to Santos and Santos (2005), market efficiency is categorized as weak, semi-strong and strong. The market is efficient in the weak form when asset prices incorporate information passed, for example, the financial statements for the period ended.

Haugen (2001) also introduced three versions on the market efficiency hypothesis, and the strong, semi-strong and the weak. Basically, the difference between the three is given the type of information that is available to the investor. The strong form, states that asset prices reflect all information being applied, being public, private information or even confidential information about that asset.

According to Haugen (2001), the semi-strong HEM version features the incorporation of public information assets that are available and that are relevant to the financial statements of the company which can take on the fundamental analysis, for example. In this case, no public information-based analysis will identify sub or super assets evaluated as analysts incorporated the information in your analysis model and the asset price is stable in the market.

Camargos (2006), which sought to analyze whether the Brazilian capital market began to show the level of semi-strong efficiency through event study of merger and acquisition announcements, shows that the behavior of the cumulative abnormal returns in the event window evidenced the lack of standard behavior for the series as a whole and evidence that on day t1 there was a significant increase in abnormal returns, that is, a positive and instantaneous reaction of the market to the merger or acquisition processes, but not in an efficient way. A possible cause of this inefficiency would be associated with macroeconomic variables (systematic risk) and the peculiarities of the Brazilian capital market.

Regarding the weak version of HEM, Haugen (2001) performed tests stating that asset prices incorporate all possible information, observing the history of the pricing itself. If the past can explain the future, market agents can use the signals pointed out in the past and soon these signals would lose value, since analysts who saw the same signs would act in the market and prices would adjust in order to incorporate these movements. HEM in its weak form suggests that asset prices have a random behavior, called random walk, and since they are random, there is no correlation between past and future prices.

Aldrighi (2005), on the other hand, researched the connection between HEM and on Behavioral Finance, moved by the attempt to explain these "market anomalies", rejects the assumption of unlimited rationality and adopts a perspective that incorporates contributions from Psychology and Sociology. Finally, the survey also deals with the failure of the arbitration issue to eliminate the systematic errors of assessment of probabilities and forecast values.

When addressing the random walk, Santos and Santos (2005) researched the modification of the expected return on the asset, the variation in asset prices occurring whenever any new information appears. Brandão (2009), defines the random walk as a model where the returns are independent and identically distributed. If asset prices really behave like a random walk, it 
would validate HEM in its weak form, then there is no reason to justify any investment strategy based solely on past information leading to significantly non-zero returns.

\subsection{Behavioral Finance}

In the most discussed topics within behavioral finance, Lima (2003), SHEFRIN argues that some psychological phenomena are spread across all fields of Finance. Shefrin met these phenomena on three themes to make them clearer.

- Heuristic bias (1st theme): Do financial agents make mistakes by believing in assumptions? The followers of Behavioral Finance answer yes, and the followers of the Traditional Model of Finance answer are negative. Behavioral Finance recognizes that practitioners use assumptions called heuristics to process information.

- Subordination to Form (2nd Theme): Does the form or structure the problem presents influence practitioners? Shefrin assumes that in addition to the objective considerations, the perception of risk and return practitioners is highly influenced by how problems are structured and displayed. On the other hand, Traditional Finance theory postulates that agents see all decisions through the transparent and objective lenses of risk and return.

- Inefficient Markets (3rd Theme): Do errors and different problem structures affect the prices established in the market? The last two topics covered are cited by behavioral finance supporters as those responsible for making market prices deviate from fundamental values. The Traditional Theory of Finance admits the market as efficient, contradicting, therefore, the previous themes.

Some less extremists try to reconcile these two seemingly contrasting models, seeking to see the Behavioral Finance not as an opponent, but rather as an improvement of the Model Modern Finance. This idea assumes that today's sophisticated mathematical models are not useless, should only be improved further by incorporating studies of the irrationality of investor.

\section{Methodology Analysis Procedure}

As source methodology, the calculations for this study are similar to that applied in HotzBehofsits search; Huber and Zorner (2018), that to deal with the dimensionality was necessary to introduce prior recent shrinkage (Feldkircher, Huber, \& Kastner, 2017) and a flexible specification for the law of motion of the regression parameters (Huber, Kastner \& Feldkircher; 2017). Moreover, it was important to introduce a heavy-tailed distribution measurement error for potential peripheral observations capture (Carlin, Polson, \& Stoffer, 1992; Geweke and Tanizaki, 2001).

What differs from the search Hotz-Behofsits et al (2018) for this study is the fact that the analysis be performed by a longer period (between 2017 and 2019), treat the bitcoin prices alone, does not meet the stock indices Values, since it is not the objective of this research, and prices are analyzed in their daily quotations.

This study was based on econometric statistics tools using data collected from exchanges in Brazil, United States and Europe, between August 1, 2017 until May 31, 2019, with trading data with daily frequency, totaling 2,106 observations. 
The data were collected from the website www.bitcoinchart.com, which has cryptocurrency trading data storage. Using the Stata ${ }^{\circledR}$ software, analyzes were performed.

The variables used in the model were Veur - Variation of virtual currency in relation to the Euro, Vbrl - the virtual currency variation over the Brazilian Real, Vusd - the virtual currency fluctuation in relation to the dollar.

The unit root tests of Dickey-Fuller and Phillips-Perron, for all currencies being BRL, EUR and USD. The best number of lags for the multivariate system, defined by the information criteria Akaike Information Criterion (AIC), Schwarz Bayesian Information Criterion (SBIC), Hannan Quinn (HQIC) and Final Predictor Error (FPE), detailed in LUTKHEPOL (1993).

To allow independence between the series data, instead of raw data, the return was calculated using the Neperian logarithm between the data collected from these operations. When dealing with returns, effects exogenous to the specific variation of exchange rate and inflation of the object of study were eliminated.

The choice of Bitcoin was made because it is one of the main entry currencies among the other cryptocurrencies and because it has a high liquidity index, because if the method of choice was a cryptocurrency with restricted or limited liquidity, the results of this research could be skewed.

\section{Data Obtained}

Initially, to analyze the market's volatility of, it was seen that the standard deviations of the series are very close to each other, the means and medians are also corresponding to the standard deviation. Also analyzing the variation coefficient, the same results were obtained, that the series have close volatilities, as we can see in chart 1 .

Chart 1: standard deviation, average, median and coefficient of variation of the series USD, EUR and BRL Exchange of surveyed 2017 to 201.

Source: done by the authors.

\begin{tabular}{|l|c|c|c|}
\hline \multicolumn{1}{|c|}{ Descritivo } & Gdax & \multicolumn{1}{c|}{ Kraken } & MB \\
\hline Desvio Padrão & 0,0454122 & 0,0450264 & 0,4361020 \\
\hline Média & 0,0016928 & 0,0017351 & 0,0019021 \\
\hline Mediana & 0,0015700 & 0,0017900 & 0,0017950 \\
\hline $\begin{array}{l}\text { Coeficiente de } \\
\text { Variação }\end{array}$ & 26,8266800 & 25,9503200 & 22,9274000 \\
\hline
\end{tabular}

In general, the series are stationary, that is, they will return to the historical average, which confirms that there is no unit root. The tests, as Table 2 and Figure 1, confirms that the series is stationary in level, rejecting the null hypothesis of the presence of unitary root.

As the series are stationary, there is cointegration between any combination of them, and the BRL and EUR pairs, BRL and USD, EUR and USD, BRL and EUR and USD.

It was also observed in the cointegration tests, spurious regression, caused by outliers, 18 observations, causing a delay to the price in BRL be reconfigured to other markets. 
Graph 1: box plot of the data series in search order USD / EUR, BRL / EUR respectively.

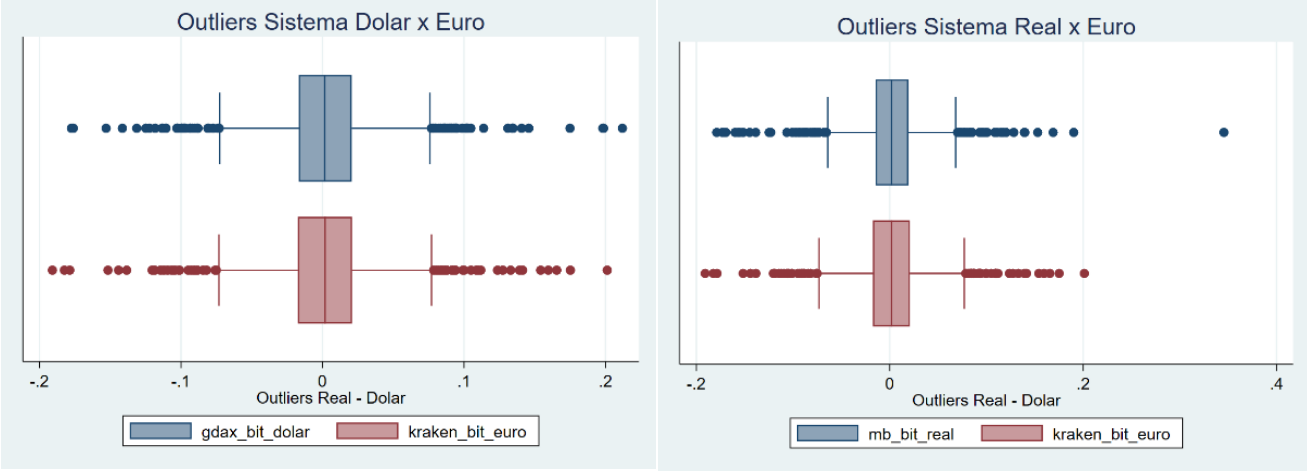

Source: done by the authors.

By analyzing the individual series, as shown in chart 2 and chart 3, in the system between EUR and USD there is a cointegration equation, and its last price, is influenced by three lags. When performing the cointegration test, using the lags found.

Chart 2: Dickey-Fuller unit root tests for researched data series

Interpolated Values Dickey - Fuller

$10 \%$ Critical

\begin{tabular}{lcccc} 
& Test Statistic & $1 \%$ Critical Value & $5 \%$ Critical Value & Value \\
\hline BRL & $-25,721$ & $-3,430$ & $-2,860$ & $-2,570$ \\
EURO & $-27,005$ & $-3,430$ & $-2,860$ & $-2,570$ \\
DOLAR & $-26,854$ & $-3,430$ & $-2,860$ & $-2,570$ \\
\hline
\end{tabular}

Source: done by the authors.

Chart 3: Determining the pair of delays number of series Dollar (USD) versus the Euro (EUR).

Sistema: USD x EUR

\begin{tabular}{|c|c|c|c|c|c|c|c|c|}
\hline lag & $\mathrm{LL}$ & LR & $\mathrm{df}$ & $P$ & FPE & AIC & $\mathrm{HQIC}$ & SBIC \\
\hline 0 & $3.462,17$ & & & & $1,6 \mathrm{e}-07$ & 9,94301 & 9,93796 & 9,92995 \\
\hline 1 & $35,08,03$ & 91,7340 & 4 & - & $1,5 e-07$ & 10,06330 & 10,04820 & 10,02410 \\
\hline 2 & $3.531,48$ & 46,8840 & 4 & - & $\quad 1,4 e-07$ & - 10,11920 & $-10,0939 *$ & $-10,0539 *$ \\
\hline 3 & $3.536,65$ & $10,342^{*}$ & 4 & 0,035 & $1,4 \mathrm{e}-07^{*}$ & $-10,1225^{*}$ & 10,08720 & 10,03110 \\
\hline 4 & $3.539,46$ & 5,6338 & 4 & 0,228 & $1,4 \mathrm{e}-07 *$ & - 10,11910 & 10,07370 & 10,00160 \\
\hline
\end{tabular}

Source: done by the authors.

R). Source: done by the authors.

In the series analyzed between EUR and BRL, as shown in chart 2 and chart 4, three lags were found to explain the current price of the EUR, however, it can be seen that in the equation, the EUR's past has significance in the second lag of the price of BRL price, however, the BRL does not have any significance in the price of EUR. 
Chart 4: Determination of the number of delays in the pair of Brazilian Real (BRL) versus Euro (EUR) series.

Sistema: EUR x BRL

\begin{tabular}{|c|c|c|c|c|c|c|c|c|}
\hline lag & $\mathrm{LL}$ & LR & $\mathrm{df}$ & $\mathrm{P}$ & FPE & AIC & $\mathrm{HQIC}$ & SBIC \\
\hline 0 & $2.790,77$ & & & & 1,1e-06 & 8,01372 & 8,00867 & 8,00066 \\
\hline 1 & $2.845,80$ & 110,0500 & 4 & - & $9,8 e-07$ & 8,16033 & 8,14518 & 8,12115 \\
\hline 2 & $2.861,14$ & 30,6900 & 4 & - & $9,5 e-07$ & 8,19293 & $-8,16768 *$ & $-8,12763 *$ \\
\hline 3 & $2.866,37$ & $10,456^{*}$ & 4 & 0,033 & $9,4 \mathrm{e}-07^{*}$ & $-8,19646^{*}$ & 8,16111 & 8,10503 \\
\hline 4 & $2.869,90$ & 7,0681 & 4 & 0,132 & $9,5 e-07$ & 8,19512 & 8,14967 & 8,07757 \\
\hline
\end{tabular}

Source: done by the authors

In the EUR x BRL system, in the BRL equation, your quotation reinforces itself, the last quote has significance in the current price, that is, EUR directs the BRL quotation downwards, in the second BRL lag, the price in EUR is also directed in the same direction. The error correction mechanism is working, showing that the system is self-balancing and that the BRL quotation influences the EUR one.

Figure 2: stability map of the coefficients of the 3 systems studied. Parameter stability, in order $U S D$ / BRL, BRL / EUR, USD / EUR / BRL respectively.
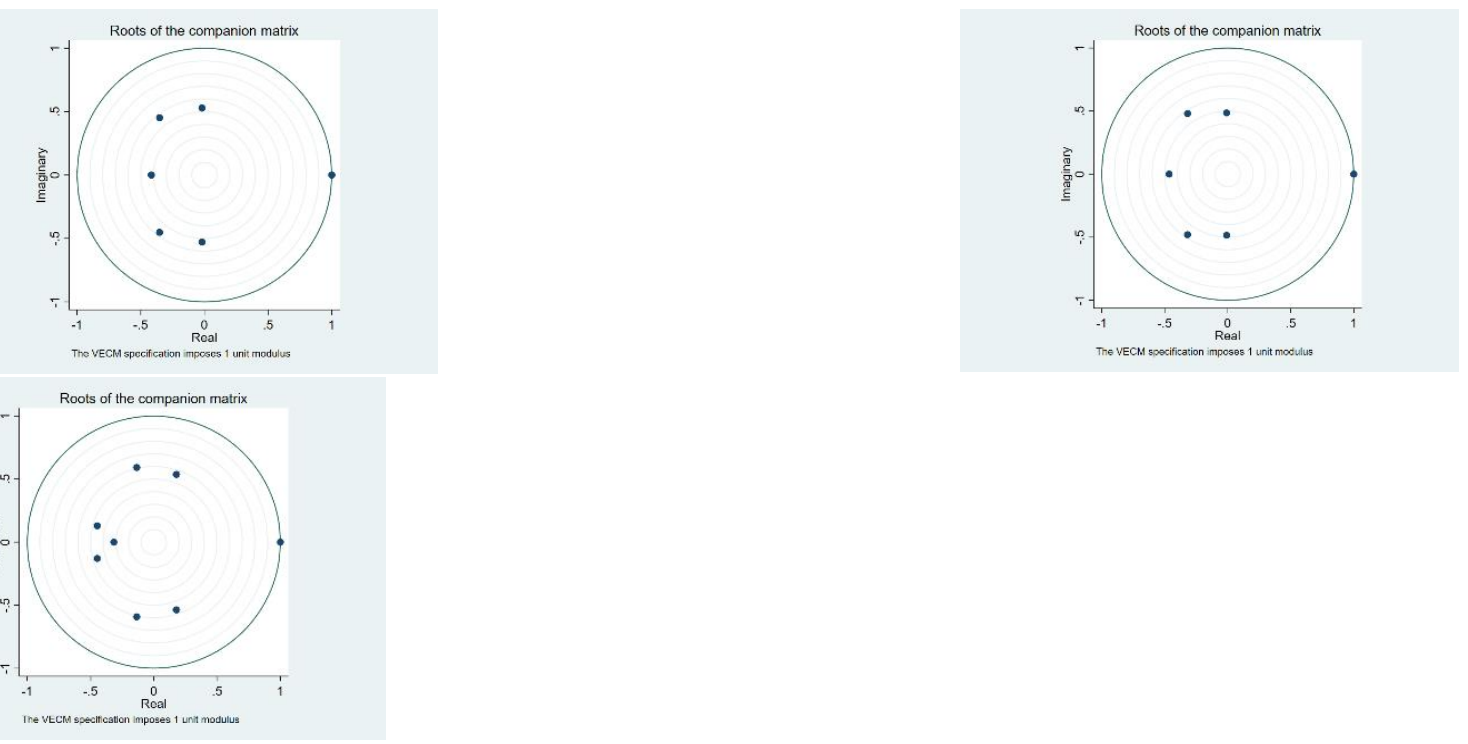

Source: done by the authors.

The outlier found performs at one time quote for BRL which is outside the standard of the other systems, which corroborates the conclusion of market liquidity problem, since the price of BRL has a longer time to be corrected other systems studied, that is, this explanation can be found by the sudden movement of the market price by volume, volatility and liquidity markets have between exchanges and countries. 


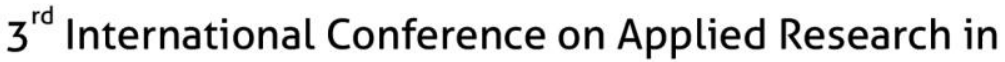 MANAGEMENT, ECONOMICS and ACCOUNTING}

In USD and BRL series in graph 1 and chart 2 and chart 5, the number of asymmetry coefficients are normal, since the observations are around converging average. In unit root test, it can be seen that four lags are what explains its last value, and presents cointegration with one, three and four lags of the series. The error correction mechanism is consistent with the test and, finally, the last price of the series itself justifies the price quote with a significance of $1 \%$.

Chart 5: Determination of the pair of delays number of US Dollars series (BRL) versus

Dollar (USD).

\begin{tabular}{|c|c|c|c|c|c|c|c|c|}
\hline lag & $\mathrm{LL}$ & LR & $\mathrm{df}$ & $\mathrm{P}$ & FPE & AIC & $\mathrm{HQIC}$ & SBIC \\
\hline 0 & $2.804,69$ & & & & 1,1e-06 & 8,05371 & 8,04866 & 8,04064 \\
\hline 1 & $2.840,45$ & 71,5140 & 4 & - & $9,9 e-07$ & 8,14497 & 8,12982 & $-8,10578 *$ \\
\hline 2 & $2.852,72$ & 24,5380 & 4 & - & $9,7 e-07$ & 8,16873 & 8,14348 & 8,10342 \\
\hline 3 & $2.861,73$ & $18,025^{*}$ & 4 & 0,001 & $9,6 e-07$ & 8,18313 & $-8,14778 *$ & 8,09170 \\
\hline 4 & $2.866,22$ & 8,9858 & 4 & 0,061 & $9,6 \mathrm{e}-07^{*}$ & $-8,18455^{*}$ & 8,13910 & 8,06700 \\
\hline
\end{tabular}

Source: done by the authors.

In the series between EUR and USD, the markets are cointegrated and the lag of the last price correction is due within three lags. In the USD equation, the quote itself is explained by itself, since its last price, within the error correction mechanism, is consistent with the test. In the EUR equation, there is no explanation to justify the quotation price in USD, since the error correction test mechanism does not work, thus, the quotation of the price in EUR does not explain its own spot price.

\section{Analysis Results}

The study aimed to examine whether bitcoin trading markets respect the efficient market hypothesis, studying three trading markets, and the Brazilian, European and American.

According to the data and tests carried out, it can be seen that the efficiency of the cryptocurrency market is strong, since the last past values justify its net present value, and that the price balance occurs in a lag of only 60 minutes.

The cointegration tests show us that, in the EUR and USD equations, their last three values are statistically significant at the level of $1 \%$ for determining their present value (spot), while in the BRL equations, the tests showed mostly that only the last price is statistically significant at $1 \%$.

This evidence, of strong market efficiency, can be justified by the speed at which information flows within the world of cryptocurrencies, and also, by the market not having limited hours of operation, thus, news that occurs in Europe is easily and quickly impacted the price of the Brazilian market, since the operations do not have opening and / or closing and the information is conveyed in real time around the world.

In the USD system, all past dollar values influence their own current value (spot) in the BRL equation, and no past USD equation justifies and influences the present USD value. It was 
also found that the past values of the BRL do not justify its present value, but the past value of the USD justifies the present value of the BRL, also in line with the liquidity and significance of the market, since the volume traded in USD is approximately eighty times the volume traded in BRL. As the error correction mechanism occurs for the dollar, we conclude that the USD market drives the quotation prices in the BRL system, finally, the data show that the USD system is the one that defines the BRL quotation.

In the EUR equation, it is identified that the EUR has no influence on the USD quotation, the error correction mechanism does not work in this equation, which leads us to believe that the EUR quotation also does not explain the EUR quotation itself, as it was identified that the EUR market has less liquidity than the USD, and the dollar market is six times larger than the euro market, the equation conclusions are easily observed in market practice. Finally, the EUR system does not converge the average itself, as it follows the quotation in USD, the latter, forces converge average, since the market in USD converges average.

When analyzing the USD equation, its past significantly affects the euro, since the euro itself does not affect its quotation, it is noticed that the cointegration equation is significantly at $1 \%$ between the series and the coefficients of the integration equation are aligned.

The correction of the euro and dollar system occurs due to the euro quotation, in other words, it was identified that the USD is the market driver, directing and aligning the rest of the systems and the market as a whole.

When the price is taking off between BRL systems, USD and EUR, the quotation price of EUR holds the price of USD to stabilize pricing, operating as a brake on volatility, by observation, can see that this maneuver can occur through the market player performing arbitrage in the two different markets, and this difference decreases when financial institutions are in full operation, which allows currency to be transited outside the cryptocurrency system, which generates the settlement and the opportunity to perform the arbitration gear again finally, the mechanism is corrected by the euro in this system.

The instability of all systems is being driven by the dollar exchange rate, since it is the driver of the entire market according to the series studied. Its quotation is positioning the other quotations in EUR and BRL, which, in turn, insures price corrections in other markets due to the lack of the same liquidity as the USD system, or by the performance of arbitrators or by the natural correction of the markets.

In the systems equation involving BRL and EUR, until the third day, the information of the above quotations are loaded to justify the current price, which shows that the market is not efficient, since market efficiency assumes that the last value (a day spent) the information is incorporated into the price to compose the current price (spot).

\section{Conclusion}

By analyzing the volatility tests, we can see that in addition to the series is cointegrated, still have the same movement and volatility remains at the same level, to be treated.

In the case of outliers found in the time series, as seen in graph 1 , it can be said that the amount is not significant for interference with the whole system being irrelevant to the whole set. The identified outlier can be explained by the lack of market liquidity in BRL, as the volatility of the three sets (BRL, EUR, USD) can be high, the correction of prices in your local markets can vary according to the market liquidity, thus, a large sudden change in price 
in USD may have a time lag in BRL price for liquidity in the latter is less like the first, for example. Corroborating the Valente, Forte and Hadad (2020) research, when testing the USD, EUR and BRL markets at 15-minute intervals.

It can also be concluded that the dollar equation, its last price quotation is justified by itself, and the first and second time lags in the BRL may explain the price of the dollar, this position can be seen that in this series the price in BRL retains system information until the USD quote is explained, is also justified by market liquidity. In BRL equation, the behavior is analogous.

Thus, you can see that the Efficient Market Hypothesis is also present in the new cryptocurrency market, in its weak form in the BRL and EUR system, since only in the third lag is the current price justified, the market information, with the speed of traffic information, has already been absorbed by the market almost instantly, which does not happen with the USD system, where its last price is justified by itself, that is, all information has been absorbed, the market cointegrates at the same time and its pricing is corrected.

Finally, it can be seen that a theory of Finance Modern Traditional integrates with the Behavioral Finance Theories, since studies and financial market theories that exist before the emergence of disruptive market cryptocurrencies converges and suites to the studies of behavioral finances, which shows us a vast space for developing new research and deepening the understanding of this market, this technology and its functions, once again, we are facing something new, and as the current technology, which seems to pass faster, however, this time, we are looking from the inside and seeing how it works.

The limitations of this research, the traditional market does not allow us to deepen a study of events, since the crypto asset market works twenty-four hours a day and seven days a week, a study on whether there is a greater possibility of arbitration or comparative when the financial institutions that move fiat currency are working is valid.

It is also possible to highlight a technological limitation to determine the data for high frequency, since the time of this research, we can't analyze all negotiations reproducing negotiations me real-time due to lack of computing power, is suggested for future studies.

\section{References}

[1] Aldrighi, Dante Mendes; Milanez, Daniel Yabe. Finança Comportamental e a hipótese dos mercados eficientes. R. Econ. Contemp., Riode Janeiro, 9 (1): 41-72, jan/abr. 2005

[2] Bone, Rosemarie Broker; Ribeiro, Eduardo Pontual. Eficiencia Fraca, Efeito Dia-daSemana e Efeito Feriado no mercado Acionário Brasleiro: Uma Análise Empírica Sistemática e Robusta. RAC, v.6, n.1, Jan/abr. 2002

[3] Caldeira, J.F.; Moura, G.V.; Santos, A.A.P. Tessari, C. Seleção de carteiras com modelos fatoriais heterocedásticos: Aplicação para fundos de fundos multimercados. Revista de Administração Mackenzie, 15(2), 127-161. Doi:10.1590/S1678-69712014000200006. 2014

[4] Chan, Stephen; Chu, Jeffrey; Nadarajah, Saralees; Osterrieder, Joerg. A Statistical Analysis of Cryptocurrencies. Journal of Risk and Financial Management. May/2017

[5] Darrat, Ali F; Zhong, Maosen. On Testing the Random-Walk Hypothesis: A ModelComparison Approach. The Financial Review 35. P 105-124. 2000 
[6] Fama, E. e French, K. "Permanent and Temporary Components of Stock Prices", Journal of Political Economy, 96: 301-325. 1988

[7] Fama, E.F. Efficient Capital Markets: A Review of Theory and Empirical Work, Journal of Finance, v. 25, p. 383-417, 1970.

[8] Hotz-behofsits, Christian; Huber, Florian; Zorner, Thomas Otto. Predicting cryptocurrencies using sparse non-Gaussian state space models. Journal of Forecasting. DOI: 10 1002/for.2524. February/2018

[9] Phillip, Andrew; Chan, JenniferS.K.; Peiris, Shelton. A new look at Cryptocurrencies. Journal Elsevier - Economic Letters. Nov/2017

[10] Rabelo Junior, Tarcísio Saraia; Ikeda, Ricardo Hirata. Mercados eficientes e arbitragem: um estudo sob o enfoque das finanças comportamentais. Revista Contabilidade \& Finanças - USP, São Paulo, n.24, p 97-107, janeiro/abril. 2004

[11] Valente Filho, João; Forte, Denis; Haddad Junior, Eli. ARE CRYPTOCURRENCIES UNBIASED? THE CASE OF BITCOIN IN BRAZIL. Aplied Management Finances. AMA21.2020 